\title{
Survey on the Consciousness of Japanese Women Regarding Dense Breasts on Mammography
}

\author{
Ikumi Kataoka', Ryuko Kawashima², Yumiko Tsubota ${ }^{3}$, Yumiko Fukkoshi', \\ Hiroaki Kawashima5, Haruhiko Fukuta6, Ikuo Kashiwakura1 ${ }^{*}$ \\ ${ }^{1}$ Department of Radiation Science, Graduate School of Health Sciences, Hirosaki University, Hirosaki, Aomori, Japan \\ ${ }^{2}$ Tsugaru Citizen Clinic, Aomori, Japan \\ ${ }^{3}$ Aomori General Health Examination Center, Aomori, Japan \\ ${ }^{4}$ Public Noheji Hospital, Kamikitagun-Nohejimachi, Aomori, Japan \\ ${ }^{5}$ Aomori City Hospital, Aomori, Japan \\ ${ }^{6}$ Medical Court Hachinohe-Nishi Hospital, Hachinohe, Aomori, Japan \\ Email: ^ikashi@hirosaki-u.ac.jp
}

How to cite this paper: Kataoka, I., Kawashima, R., Tsubota, Y., Fukkoshi, Y., Kawashima, H., Fukuta, H. and Kashiwakura, I. (2019) Survey on the Consciousness of Japanese Women Regarding Dense Breasts on Mammography. Advances in Breast Cancer Research, 8, 135-146.

https://doi.org/10.4236/abcr.2019.84010

Received: July 19, 2019

Accepted: September 17, 2019

Published: September 20, 2019

Copyright (c) 2019 by author(s) and Scientific Research Publishing Inc. This work is licensed under the Creative Commons Attribution International License (CC BY 4.0).

http://creativecommons.org/licenses/by/4.0/

\begin{abstract}
Patients with dense breasts on mammography have a higher risk of developing breast cancer and missing a tumor mass than those with non-dense breasts. Whether examinees who have dense breasts should be notified is currently under consideration in Japan; however, there is concern about the low level of understanding regarding dense breasts. A questionnaire survey on the degree of comprehension regarding dense breasts was conducted among 409 general women of $>20$ years of age in Hachinohe city in October 2017 and 2018. The results showed that the degree of comprehension was extremely low, as only 35 people (8.5\%) responded with, "I know the meaning"; however, 32 of them (91.5\%) stated that they would like to be notified in they had dense breasts. In addition, the degree of comprehension regarding dense breasts was significantly greater among those who had a breast cancer screening history $(\mathrm{OR}=6.4 ; 95 \% \mathrm{CI}=2.0-19.8 ; \mathrm{P}=0.001)$ and $\mathrm{a}$ self-examination history than among those with no such history $(\mathrm{OR}=2.5$; $95 \% \mathrm{CI}=1.1-5.8 ; \mathrm{P}=0.03)$. However, the degree of comprehension did not differ between participants of $<40$ and $\geq 40$ years of age or between participants with and without a breast cancer sufferer among their close blood relatives. The present findings to reflect a low understanding of dense breasts on mammography screening and suggest that the degree of comprehension is influenced by the presence or absence of a consultation history and a self-examination history.
\end{abstract}




\section{Keywords}

Dense Breasts, Comprehension, Notification, Breast Cancer Screening, Japan

\section{Introduction}

Although screening mammography is the only examination that has been proven to lead a decrease in the mortality rate of breast cancer patients [1] [2], it is difficult to detect mass lesions in patients with dense breasts [3]. Thus, the topic of dense breasts has been a frequent point of discussion since screening mammography was introduced for Japanese women in their $40 \mathrm{~s}$ [4] [5]. The screening sensitivity in patients with dense breasts is lower than that in patients with non-dense breasts [6]. The proportion of Japanese women with dense breasts is approximately $40 \%$; importantly, $54.9 \%$ - 68.8\% of Japanese women in their $40 \mathrm{~s}$ have dense breasts [7]. For this reason, the patient association wished to notify examinees with dense breasts. In 2018, the Ministry of Health, Labor and Welfare of Japan recommended that the recommendation of uniform notifications is premature. However, according to the survey, the notification of women with dense breasts had already been implemented by of $13.5 \%$ of the 1700 municipalities that responded, and $7.8 \%$ of the municipalities that had not implemented this practice expected to do so in the future [8].

Currently, there is no evidence-based standard for the handling notifications regarding dense breasts. The practice varies from country to country. Notification has not been implemented in any countries in Europe [9]. In the United States, legislation on the notification of mammary gland density was enacted in 2009 (Breast Density Notification Laws), and 31 of the 50 states notify women about dense breasts [10]. A review reported that most women with dense breasts in the United States were unaware that they had dense breasts, and that some women do not understand the meaning of the term "dense breasts" [11]. Dense breasts are recognized as a risk factor for breast cancer [12]. Thus, more people feel uneasy about the risk of developing breast cancer when they learn about their mammary gland density [13]. It is possible that a low level of understanding regarding dense breasts, leads to increased anxiety and additional examinations. In Japan, the degree of comprehension regarding dense breasts is not clear. In addition, women under 40 of age will soon be subject to mammography and it is important to assess whether or not they understand the concept of dense breasts. However, little research has been done to investigate the actual level of understanding.

The aim of this study was to clarify the degree of comprehension regarding dense breasts, the wishes of women regarding notification about dense breasts, and the factors influencing the degree of comprehension regarding dense breasts among women older than 20 years of age. 


\section{Methods}

\subsection{Study Participants and Survey Method}

This study examined women $\geq 20$ years of age who visited a shopping mall in Hachinohe, and who agreed to participate in the questionnaire survey (the place of residence was not specified). We surveyed 187 women in October 2017 and 241 women in October 2018. Nineteen women who had been investigated at both points were excluded, giving a final sample of 409 women. The data were collected by four surveyors who were medical radiologists and clinical laboratory technicians. They asked the participants the questions on the sheet and filled in their answers. The questionnaires included three major items: 1) participant characteristics (age, birth experience, breast-feeding experience, presence of breast cancer sufferers among close blood relatives); 2) behavior regarding breast cancer screening (history of breast cancer screening, interval of examination, content of examination); and 3) questions related to dense breasts (degree of comprehension regarding dense breasts, sources of information about dense breasts, wishes regarding dense breast notification). The sources of information on dense breasts were only investigated in 2018 .

This study received the approval of the Ethics Committee of the Graduate School of Health Sciences, Hirosaki University (Reference number: 2017-035). The choice to participate in the survey was freely made. The purpose of the survey was explained and informed consent was obtained from the study participants, including consent to participate and to publish the findings.

\subsection{Data Analyses}

The breast cancer screening behavior was compared between participants of $<40$ years of age and those of $\geq 40$ years of age using the $\chi^{2}$ test. The relationship between the degree of comprehension regarding dense breasts and the characteristics of the participants and the history of breast cancer screening was analyzed using a multivariate logistic regression analysis. The degree of comprehension regarding dense breasts was the objective variable. Participants were classified into three groups according to their degree of comprehension regarding dense breasts. Those who responded "I know the meaning of the term" were considered to understand the term, while those who responded that "I have only heard the term" and "I do not know the meaning of the term" were considered to not understand the meaning of the term and were grouped together. Four items were included as explanatory variables: $<40$ and $\geq 40$ years of age, presence of breast cancer sufferers among close blood relatives (first-degree and seconddegree relatives), history of breast cancer screening, and history of breast self-examination. All statistical analyses were performed using the Excel (Microsoft, Redmond, WA, USA) and R (version 2.8.1, The R Foundation for Statistical Computing, Vienna, Austria) software programs. P-value of $<0.05$ was considered to indicate statistical significance. 


\section{Results}

\subsection{Participant Characteristics}

Table 1 shows the characteristics of the participants; $37.6 \%$ of the participants were in their $30 \mathrm{~s}$ and $22.7 \%$ were in their $40 \mathrm{~s}$; these 2 groups accounted for $60.3 \%$ of the overall population. Among the participants $91.9 \%$ of the women had birth experience $89.2 \%$ had breast-feeding experience, and $13.0 \%$ had a breast cancer sufferer among their close blood relatives (first-degree and seconddegree relatives; grandmother or aunt, 54.7\%; mother, 30.2\%).

\subsection{Breast Cancer Screening Behavior}

Table 2 shows the breast cancer screening behavior. In Japan, mammography screening for breast cancer is targeted at women $\geq 40$ years of age. Therefore, we compared women $<40$ years of age who were not targets of mammography screening and those $\geq 40$ years of age who are targets. In the overall population, $57.5 \%$ of the women had experienced breast cancer screening, $49.8 \%$ of these women underwent regular screening (every year or every other year). $43.8 \%$ of the women received mammography alone, $13.2 \%$ of the women received ultrasonography alone, and $43.0 \%$ of the women received both. In the overall population, $53.8 \%$ of women performed self-examinations, with $20.0 \%$ performing self-examinations monthly. When the women were divided according to their

Table 1. Participant characteristics.

\begin{tabular}{|c|c|c|c|}
\hline \multirow[b]{2}{*}{ Age } & \multirow[b]{2}{*}{$20 \mathrm{~s}$} & \multicolumn{2}{|c|}{$\mathrm{n}(\%)$} \\
\hline & & 54 & $(13.2)$ \\
\hline & $30 \mathrm{~s}$ & 154 & $(37.6)$ \\
\hline & $40 \mathrm{~s}$ & 93 & $(22.7)$ \\
\hline & $50 \mathrm{~s}$ & 35 & $(8.6)$ \\
\hline & $60 \mathrm{~s}$ & 49 & $(12.0)$ \\
\hline & $70 \mathrm{~s}+$ & 24 & $(5.9)$ \\
\hline \multirow[t]{2}{*}{ Birth experience } & Yes & 376 & $(91.9)$ \\
\hline & No & 33 & $(8.1)$ \\
\hline \multirow[t]{2}{*}{ Breastfeeding experience } & Yes & 365 & $(89.2)$ \\
\hline & No & 44 & $(10.8)$ \\
\hline Presence of breast cancer sufferers & Yes & 53 & $(13.0)$ \\
\hline \multirow[t]{5}{*}{ Among close blood relatives } & mother & 16 & $(30.2)$ \\
\hline & sister & 7 & $(13.2)$ \\
\hline & children & 1 & (1.9) \\
\hline & grandmother/aunt & 29 & $(54.7)$ \\
\hline & No & 356 & $(87.0)$ \\
\hline $\mathrm{n}=409$ & & & \\
\hline
\end{tabular}


Table 2. Breast cancer screening behavior.

\begin{tabular}{|c|c|c|c|}
\hline & $\begin{array}{c}\text { Overall }^{\mathrm{a}} \\
\mathrm{n}(\%)\end{array}$ & $\begin{array}{l}<40^{\mathrm{b}} \\
\mathrm{n}(\%)\end{array}$ & $\begin{array}{l}\geq 40^{\mathrm{c}} \\
\mathrm{n}(\%)\end{array}$ \\
\hline \multicolumn{4}{|c|}{ Have you ever undergone breast cancer screening? screening? examination? } \\
\hline Yes & $235(57.5)$ & $69(33.2)$ & $166(82.6)^{\mathrm{c}}$ \\
\hline \multicolumn{4}{|c|}{ Interval of examination } \\
\hline regularly & $117(49.8)$ & $32(46.4)$ & $85(51.2)^{\mathrm{d}}$ \\
\hline sometimes & $50(21.3)$ & $14(20.3)$ & $36(21.7)^{\mathrm{d}}$ \\
\hline previous once & $68(28.9)$ & $23(33.3)$ & $45(27.1)^{\mathrm{d}}$ \\
\hline \multicolumn{4}{|c|}{ Content of examination } \\
\hline mammography & $103(43.8)$ & $18(26.1)$ & $85(51.2)^{\mathrm{d}}$ \\
\hline ultrasonography & $31(13.2)$ & $27(39.1)^{\mathrm{d}}$ & $4(2.4)$ \\
\hline both & $101(43.0)$ & $24(34.8)$ & $77(46.4)^{\mathrm{d}}$ \\
\hline No & $174(42.5)$ & $139(66.8)^{\mathrm{d}}$ & $35(17.4)$ \\
\hline \multicolumn{4}{|c|}{ Do you conduct breast self-examination? } \\
\hline Yes & $220(53.8)$ & $93(44.7)$ & $127(63.2)^{c}$ \\
\hline \multicolumn{4}{|c|}{ Interval of examination } \\
\hline monthly & $44(20.0)$ & $15(16.1)$ & $29(22.8)^{\mathrm{d}}$ \\
\hline sometimes & $176(80.0)$ & $78(83.9)$ & $98(77.2)$ \\
\hline No & $189(46.2)$ & $115(55.3)^{\mathrm{d}}$ & $74(36.8)$ \\
\hline
\end{tabular}

${ }^{a} \mathrm{n}=409 ;{ }^{b} \mathrm{n}=208 ;{ }^{c} \mathrm{n}=201 ;{ }^{\mathrm{d}} \mathrm{P}<0.05<40$ vs. $\geq 40$.

age ( $<40$ and $\geq 40$ years of age), the percentages of women $\geq 40$ years of age with a history of breast cancer screening and self-examination were $82.6 \%$ and $63.2 \%$, respectively. The percentages of women with a history of breast cancer screening and self-examination in this age group were significantly larger in comparison to the women of $<40$ years of age $(\mathrm{P}<0.05)$. Among women who were $<40$ years of age, $33.2 \%$ of the participants had a history of breast cancer screening, with $46.4 \%$ undergoing regular screening. Ultrasonography was the most frequent mode of examination; only $26.1 \%$ received mammography alone. Among women of $<40$ years of age, $44.7 \%$ of the participants performed self-examinations, with $16.1 \%$ performing monthly examinations.

\subsection{Degree of Comprehension Regarding Dense Breasts and Desires Regarding Notification}

Figure 1 shows the degree of comprehension regarding dense breasts among the overall population, women of $<40$ years of age and women of $\geq 40$ years of age. We divided and compared women $<40$ years of age who were not targets of mammography screening and those $\geq 40$ years of age who were targets. Figure 2 illustrates the desires of the respondents regarding notification about dense breasts. Regarding the degree of comprehension among women of all ages, $8.5 \%$ indi 


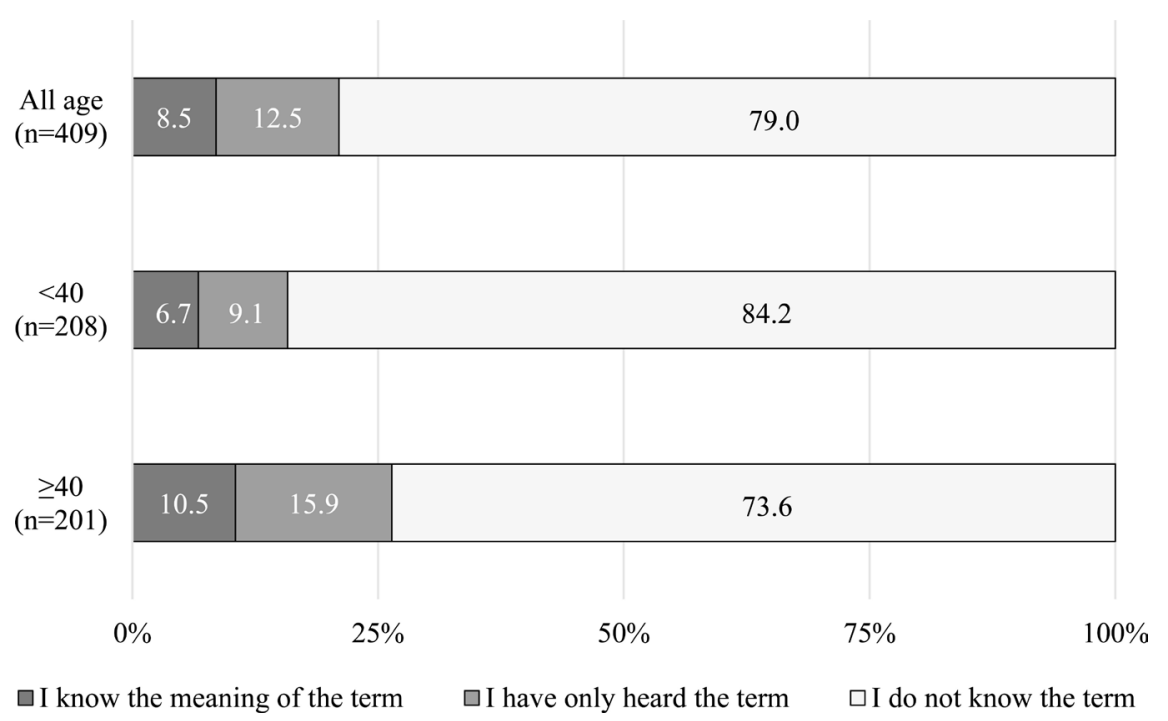

Figure 1. Degree of comprehension regarding dense breasts $(n=409)$. We conducted a survey in which subjects were asked if they knew the meaning of the term "dense breasts"? As a result, 35 people $(8.5 \%)$ indicated that they knew the meaning of the term, 51 people $(12.5 \%)$ indicated that they had only heard the term, and 323 people $(79.0 \%)$ indicated that they did not know the term. Among the participants of $<40$ years of age, $14 / 208(6.7 \%)$ indicated that they understood the term "dense breasts", and 19/208 (9.1\%) indicated that they had only heard the term. Among the participants of $>40$ years of age, $21 / 201(10.5 \%)$ indicated that they understood the term and 32/201 (15.9\%) indicated that they had only heard the term.

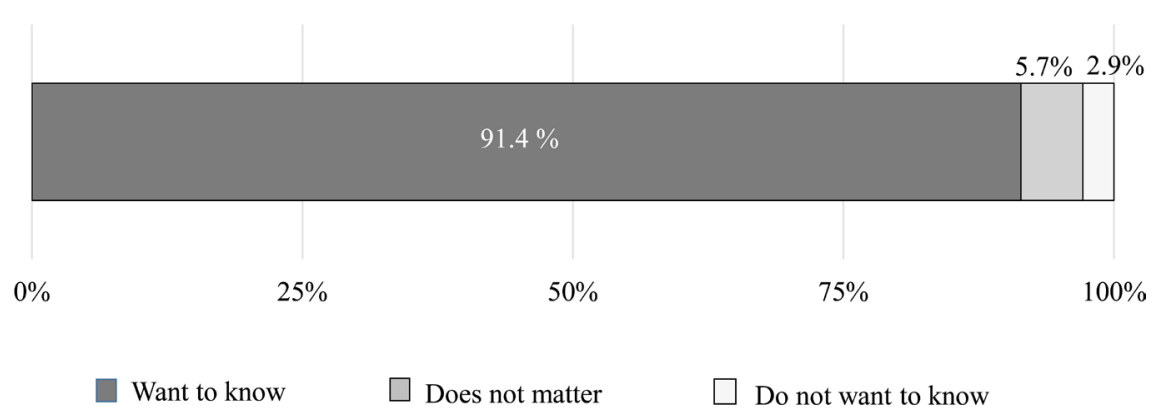

Figure 2. Desires regarding notification $(n=35)$. A survey was conducted of 35 people who indicated that they knew the meaning of dense breasts. When asked "If you were judged to have dense breasts, would you wish to be notified?", 32 people (91.4\%) indicated that they would want to know, $2(5.7 \%)$ indicated that it did not matter (either way), and 1 person (2.9\%) indicated that they would not want to know.

cated that they knew the meaning of the term, $12.5 \%$ had only heard the term, and $79.0 \%$ did not know the term. Among women of $<40$ years of age, $6.7 \%$ understood the term, 9.1\% had only heard the term, and $84.2 \%$ did not know the term. Among women of $>40$ years of age, $10.5 \%$ understood the term, $15.9 \%$ had only heard the term, and $73.6 \%$ did not know the term (Figure 1). Sources of information regarding dense breasts included media (TV/magazines) $60.0 \%$, the place of examination $6.7 \%$, and other $33.3 \%$.

Among the women who knew the meaning of the term "dense breasts", we examined the proportion of women who indicated that they wished to be noti- 
fied about dense breasts. As a result, if it was judged 91.4\% would want to know if they had dense breasts, $5.7 \%$ indicated that it would not matter, and $2.9 \%$ indicated that they would not want to know (Figure 2).

\subsection{Factors Related to the Degree of Comprehension Concerning Dense Breasts}

Table 3 shows the factors related to the degree of comprehension regarding dense breasts among the characteristics of participants and the behavior of breast cancer screening. A correlation was identified between the degree of comprehension and a history of breast cancer screening and self-examination. The degree of comprehension was significantly greater among women with a breast cancer screening history than in those with no breast cancer screening history (OR $=6.4 ; 95 \% \mathrm{CI}=2.0-19.8 ; \mathrm{P}<0.05)$, and those who had a self-examination history than in those with no self-examination history $(\mathrm{OR}=2.5 ; 95 \% \mathrm{CI}=1.1-5.8$; $\mathrm{P}<$ $0.05)$. However, there was no significant difference in the degree of comprehension of dense breast between participants of $<40$ and $\geq 40$ years of age, between participants with and without a breast cancer sufferer among their close blood relatives.

\section{Discussion}

In this study, we conducted a survey to investigate the comprehension regarding dense breasts among women (over 20 years of age) in the general population. Although we found that the degree of comprehension regarding dense breasts was low, most of the women who understood the meaning indicated that they would like to be notified if they were found to have dense breasts. Furthermore, the degree of comprehension was related to the history of breast cancer screening and self-examination.

A previous study in the United States reported that $58 \%$ of women "had heard" about dense breasts, $62 \%$ "had heard" about the risk of dense breasts, and 49\% - 53\% "knew" about the risk of dense breasts [14] [15]. However, a recent study reported that women who "knew" about the risk of dense breasts tended to increase [16]. The degree of comprehension regarding dense breasts in this study population was extremely low in comparison to the United States. This discrepancy is due in part to differences in breast cancer screening behavior among

Table 3. Relationship to the degree of comprehension on dense breasts

\begin{tabular}{ccccccc}
\hline & & & \multicolumn{2}{c}{$95 \%$ CI } & \multirow{2}{*}{ P-value } \\
\cline { 4 - 5 } & & & Odds ratio & low & up & \\
\hline < 40 vs. $\geq 40$ & & 0.7 & 0.3 & 1.5 & 0.39 \\
Breast cancer sufferers & Yes vs. No & 1.4 & 0.6 & 3.2 & 0.48 \\
Examination history & Yes vs. No & 6.4 & 2.0 & 19.8 & 0.001 \\
Self-examination history & Yes vs. No & 2.5 & 1.1 & 5.8 & 0.03 \\
\hline
\end{tabular}


participants in the study. Participants in the study in the United States, 83.3\% 91\% received breast cancer screening within $1-2$ years [14] [15]. In this study, $42.3 \%(85 / 201)$ of participants over 40 years old regularly received for breast cancer screening.

Factors reported to be related to the understanding of dense breasts were reported to include age, academic background, income, race/ethnicity, which are also factors that influence whether patients undergo breast screening examinations [11]. In this study and a previous study, comprehension of the term "dense breasts" was associated with a breast cancer screening history [17]. A close relationship can be presumed to exist between the comprehension of the term "dense breasts" and breast cancer screening history. However, more than half of the participants indicated that the media was their source of knowledge on dense breasts, and few were indicated that they received information from the place of examination. Thus, many of the participants who understood the term "dense breasts" did not receive their information from the place of examination. The participants who understood the term "dense breasts" were presumed to be interested in breast cancer screening.

The breast cancer screening rate in Japan is $41 \%$, which is lower than the rate in the United States (80.8\%; OECD, Health Statistics 2017 [18]). In addition, as a result of this survey, the degree of comprehension regarding dense breasts among women of $<40$ years of age was lower than among women of $\geq 40$ years of age. In order to improve the degree of understanding regarding dense breasts, it is necessary for women, including young women, to have more interest in breast cancer screening.

This study revealed that a large percentage of women would wish to be notified if they had dense breasts. In the United States, a survey indicated that $43 \%$ of women had an increased feeling of unease about developing breast cancer when they were informed that they had dense breasts [13]. Furthermore, notification was associated with an increase in the number of additional examinations [19]. There is a possibility that notification may be a cause of unease for the examinee and lead to an increase in additional examinations. Further studies are needed to investigate approaches regarding the notification of women with dense breasts.

This study is associated with some important limitations. The data were small and only obtained from one area of the countryside in Japan. In the future, consideration should be given to making the sample size more appropriate. The present findings, therefore, cannot be generalized to studies conducted in other regions of Japan. However, it was confirmed that these research data were similar to the data from Kawasaki City obtained by the examination committee of cancer screening of the Ministry of Health, Labor and Welfare. The data from Kawasaki City showed that, of the 1064 women who received a medical examination, $10.1 \%-20.2 \%$ understood the meaning of breast density [20]. According to the data from the present study, $13.2 \%$ of women who had a breast cancer 
screening history understood the meaning of dense breasts. This suggests that the degree of understanding the meaning of dense breast does not differ by area. Also, the breast cancer screening rate in the surveyed region is almost the same as the average breast cancer screening rate in Japan [18].

\section{Conclusion}

Our investigation showed that the degree of comprehension regarding dense breasts was low, but that most women would wish to be notified of dense breasts. It is important that many women improve their understanding of dense breasts, become interested in breast cancer screening, and undergo breast cancer screening.

\section{Acknowledgements}

We acknowledge the contribution of the Hachinohe Pink Ribbon Project, Aomori Prefecture Pink Ribbon Project, Aomori Prefecture Laboratory Technical Association, Aomori Prefecture Medical Radiation Technical Association. This study received a Grant for Scientific Research in the Master Course in Hirosaki University Graduate School of Health Sciences.

\section{Conflicts of Interest}

The authors declare no conflicts of interest regarding the publication of this paper.

\section{References}

[1] Frisell, J., Lidbrink, E., Hellström, L. and Rutqvist, L.E. (1997) Follow up after 11 Years-Update of Mortality Results in the Stockholm Mammographic Screening Trial. Breast Cancer Research and Treatment, 45, 263-270. https://doi.org/10.1023/A:1005872617944

[2] Bjurstam, N., Björneld, L., Warwick, J., Sala, E., Duffy, S.W., Nyström, L., Walker, N., Cahlin, E., Eriksson, O., Hafström, L.O., Lingaas, H., Mattsson, J., Persson, S., Rudenstam, C.M., Salander, H., Säve-Söderbergh, J. and Wahlin, T. (2003) The Gothenburg Breast Screening Trial. Cancer, 97, 2387-2396. https://doi.org/10.1002/cncr.11361

[3] Kolb, T.M., Lichy, J. and Newhouse, J.H. (2002) Comparison of the Performance of Screening Mammography, Physical Examination, and Breast US and Evaluation of Factors that Influence Them: An Analysis of 27,825 Patient Evaluations. Radiology, 225, 165-175. https://doi.org/10.1148/radiol.2251011667

[4] Endo, T., Ohuchi, N., Tsuji, I., Tohno, E., Fukuda, M., Fujita, H., Ichihara, S., Takahashi, K. and Asato, Y. (2002) Studies on the Appropriateness of Breast Cancer Screening for Women under 50 Years of Age: An Interim Report. Journal of Japan Association of Breast Cancer Screening, 11, 137-142. https://doi.org/10.3804/jjabcs.11.137

[5] Morimoto, T. (2009) A History of Breast Cancer Screening and Future Problems in Japan. Journal of Japan Association of Breast Cancer Screening, 18, 211-231. https://doi.org/10.3804/jjabcs.18.211

[6] Suzuki, A., Kuriyama, S., Kawai, M., Amari, M., Takeda, M., Ishida, T., Ohnuki, K., 
Nishino, Y., Tsuji, I., Shibuya, D. and Ohuchi, N. (2008) Age-Specific Interval Breast Cancers in Japan: Estimation of the Proper Sensitivity of Screening Using a Population-Based Cancer Registry. Cancer Science, 99, 2264-2267. https://doi.org/10.1111/j.1349-7006.2008.00926.x

[7] The Ministry of Health, Labor and Welfare (2017) Report on the Response to "Dense Breasts" Problem in Breast Cancer Screening. https://www.mhlw.go.jp/file/05-Shingikai-10901000-Kenkoukyoku-Soumuka/00001 58057.pdf (In Japanese)

[8] The Ministry of Health, Labor and Welfare (2017) Survey Results on Breast Cancer Screening.

https://www.mhlw.go.jp/file/05-Shingikai-10901000-Kenkoukyoku-Soumuka/00001 58048.pdf (In Japanese)

[9] European Society of Breast Imaging (2016) State of Screening in Europe.

https://www.sbi-online.org/Portals/0/Breast\%20Imaging\%20Symposium\%202016/Fin al\%20Presentations/4-9\%20930am\%20Forrai\%20-\%20EUSOBI\%20State\%20of\%20S creening\%20in\%20Eurpoe.pdf

[10] Are You Dense Advocacy, Inc. (2018) State Mandatory Breast Density Notification. https://www.areyoudenseadvocacy.org/

[11] Santiago-Rivas, M., Benjamin, S. and Jandorf, L. (2016) Breast Density Knowledge and Awareness: A Review of Literature. Journal of Primary Care \& Community Health, 7, 207-214. https://doi.org/10.1177/2150131916633138

[12] Pettersson, A., Graff, R.E., Ursin, G., Santos, Silva, I.D., McCormack, V., Baglietto, L., Vachon, C., Bakker, M.F., Giles, G.G., Chia, K.S., Czene, K., Eriksson, L., Hall, P., Hartman, M., Warren, R.M., et al. (2014) Mammographic Density Phenotypes and Risk of Breast Cancer: A Meta-Analysis. JNCI: Journal of the National Cancer Institute, 106, dju078. https://doi.org/10.1093/jnci/dju078

[13] Moothathu, N.S., Philpotts, L.E., Busch, S.H., Gross, C.P., Staib, L.H. and Hooley, R.J. (2017) Knowledge of Density and Screening Ultrasound. The Breast Journal, 23, 323-332. https://doi.org/10.1111/tbj.12734

[14] Rhodes, D.J., Radecki, Breitkopf, C., Ziegenfuss, J.Y., Jenkins, S.M. and Vachon, C.M. (2015) Awareness of Breast Density and Its Impact on Breast Cancer Detection and Risk. Journal of Clinical Oncology, 33, 1143-1150. https://doi.org/10.1200/JCO.2014.57.0325

[15] O’Neill, S.C., Leventhal, K.G., Scarles, M., Evans, C.N., Makariou, E., Pien, E. and Willey, S. (2014) Mammographic Breast Density as a Risk Factor for Breast Cancer: Awareness in a Recently Screened Clinical Sample. Women's Health Issues, 24, 321-326. https://doi.org/10.1016/j.whi.2014.02.005

[16] Cappello, N.M., Richetelli, D. and Lee, C.I. (2018) The Impact of Breast Density Reporting Laws on Women's Awareness of Density-Associated Risks and Conversations Regarding Supplemental Screening with Providers. Journal of the American College of Radiology, 16, 139-146. https://doi.org/10.1016/j.jacr.2018.08.009

[17] Kataoka, I., Kawashima, R., Tsubota, Y., Fukkoshi, Y., Kawashima, H., Fukuda, H. and Kashiwakura, I. (2019) Consciousness Survey of Dense Breast in Mammography Screening. Hirosaki Medical Journal, 69, 28-34.

[18] Organization for Economic Cooperation and Development, OECD Health Statistics (2017) Health Care Utilisation: Screening.

https://stats.oecd.org/index.aspx?DataSetCode=HEALTH_STAT\&_ga=2.242315650.1 $\underline{87906774.1548453053-712172069.1548453052}$

[19] Hooley, R.J., Greenberg, K.L., Stackhouse, R.M., Geisel, J.L., Butler, R.S. and Phil- 
potts, L.E. (2012) Screening US in Patients with Mammographically Dense Breasts: Initial Experience with Connecticut Public Act 09-41. Radiology, 265, 59-69. https://doi.org/10.1148/radiol.12120621

[20] The Ministry of Health, Labor and Welfare (2017) Current Status of Notification Regarding Breast Composition in Kawasaki City.

https://www.mhlw.go.jp/file/05-Shingikai-10901000-Kenkoukyoku-Soumuka/00001 58050.pdf (In Japanese) 


\section{Appendix}

\begin{tabular}{|c|c|c|}
\hline & Question item & Selection item \\
\hline \multirow[t]{3}{*}{ Q1 } & Age & $\square 20 \mathrm{~s} \square 30 \mathrm{~s} \square 40 \mathrm{~s} \square 50 \mathrm{~s} \square 60 \mathrm{~s} \square 70 \mathrm{~s}+$ \\
\hline & Birth experience & $\square$ YES \\
\hline & Breastfeeding experience & $\square$ YES \\
\hline \multirow[t]{8}{*}{ Q2 } & Have you ever undergone breast cancer screening? & $\square$ YES \\
\hline & What content of examination did you receive? & $\square$ Mammography only \\
\hline & & $\square$ Ultrasonograhy only \\
\hline & & $\square$ Both \\
\hline & & $\square \mathrm{NO}$ \\
\hline & What is the interval of examinations? & $\square$ Regularly (every year \& every other year) \\
\hline & & $\square$ Sometimes \\
\hline & & $\square$ Previous once \\
\hline \multirow[t]{12}{*}{ Q3 } & Do you know "dense breasts"? & $\square \mathrm{I}$ know the meaning the term \\
\hline & & $\square$ I had only heard the term \\
\hline & & $\square$ I do not know the term \\
\hline & If you know the meaning, where? & $\square$ Consultation \\
\hline & & $\square$ Media (TV·Magazine) \\
\hline & & $\square$ Acquaintance \\
\hline & & $\square$ Other ( \\
\hline & If you know the meaning, would you wish to be & $\square$ I would want to know \\
\hline & notified? & $\square$ It did not matter \\
\hline & & $\square$ I would not want to know. \\
\hline & Do you know that ultrasound can also breast & $\square$ YES \\
\hline & cancer screening? & $\square \mathrm{NO}$ \\
\hline \multirow[t]{8}{*}{ Q4 } & Do you conduct breast self-examination? & $\square$ Monthly \\
\hline & & $\square$ Sometimes \\
\hline & & $\square \mathrm{NO}$ \\
\hline & If you answer NO, why? & $\square$ Bothersome \\
\hline & & $\square$ Forget \\
\hline & & $\square$ I do not know how \\
\hline & & $\square$ I'm scared to find \\
\hline & & $\square$ Unnecessary \\
\hline \multirow[t]{6}{*}{ Q5 } & Do you have presence of breast cancer sufferers & $\square$ YES \\
\hline & among close blood relatives & $\square$ Mother \\
\hline & & $\square$ Sister \\
\hline & & $\square$ Children \\
\hline & & $\square$ Grandmother/aunt \\
\hline & & $\square \mathrm{NO}$ \\
\hline
\end{tabular}

